\title{
A Ouvir é que a Gente se Entende
}

FARIA, Mónica ${ }^{1}$

\section{RESUMO}

"A ouvir é que a gente se entende" é um ensaio que escrevi no início da minha pesquisa de doutoramento em 2012, estimulada pelo VIII encontro do Fórum Internacional Paulo Freire. Tudo começou em 2003 numa viagem que aproximou o Porto, Portugal e Salgueiro (Pernambuco), Brasil. Hoje, olhando para trás, percebo de que foi um momento de viragem, uma tomada de consciência sobre o que havíamos partilhado até então e sobre todas as oferendas que recebi da comunidade quilombola de Conceição das Crioulas durante a viagem a Salgueiro. Na bagagem transportava comigo não só os ensinamentos de Paulo Freire e a pedagogia crioula, que conheci na comunidade; mas também, um medo miudinho da responsabilidade que procurava assumir: queria ir viver na comunidade para estar lá, sentir o ritmo do dia a dia, ser pessoa capaz de assimilar o mundo que me rodeia procurando reinventar-me todos os dias nesta partícula que é global.

Paulo Freire. Pedagogia crioula. Ouvir.

\section{Listening is how we understand each other}

\begin{abstract}
"By listening we understand" is an essay that I wrote at the beginning of my PhD research in 2012, catalysed by the VIII meeting of the Paulo Freire International Forum. It all started in $\mathbf{2 0 0 3}$ on a trip that connected Porto in Portugal to Salgueiro in (Pernambuco), Brazil. Looking back today, I realize that this essay was a turning point, an awareness of what we had shared so far and all the offerings I received from the quilombola community of Conceição das Crioulas during the trip to Salgueiro. In my luggage I carried with me, not only Paulo Freire's teachings and creole pedagogy, which I learnt within the community but also a fear of the responsibility I sought to assume. I wanted to live in the community of Salgueiro to be there present, to feel the rhythm of its everyday life, and to be able to assimilate the world around me by attempting to reinvent myself daily in this tiny particle that is global.
\end{abstract}

\footnotetext{
${ }^{1}$ Escultora - Doutorado em Educação Artística pela Universidade do Porto. Professora Convidada da Escola de Arquitetura da Universidade do Minho (EAUM). E-mail: d8335@arquitetura.uminho.pt. Lattes: http://lattes.cnpq.br/4881369155000958. ORCID: 0000-0002-7215-7897.
} 
Paulo Freire. Crioula Pedagogy. Listening.

Ad'ascoltare le persone si capiscono

\section{RIASSUNTO}

"Ad'ascoltare le persone si capiscono" é stato un picolo articolo che ho scrito mentre facevo le indagini I doutoramento nel 2012, dopo che o conosciutto , Paulo Freire in un evento scientífico. Nel 2003 fece un commento che avvicinava a Porto, Portogallo e Salgueiro (cittá di Pernambuco), Brasile. Hoje, guardando indietro, baluardo di quello che fu un momento di coscienza che avevamo collaborato a tutte le regali ricevuti dalla comunità Quilombola di Conceição de le Crioulas in un viaggio a Salgueiro. Nel bagaglio portava con mé gli ensegnamenti de Paulo Freire e la pedagogia crioula, che conubi ne la comunità. $O$ sentito la responsabilità da assumere: volevo vivere, sentire i ritmo de le giornate, volevo esse una persona capace di sentire il mondo in torno a me, cercando de reinventarmi tutti i giorni.

Paolo Freire. Pedagogia Crioula. II Ascoltare.

\section{Escuchar: es como nos entendemos}

\section{RESUMEN}

"Al escuchar entendemos" es un ensayo que escribí al comienzo de mi investigación de doctorado en 2012, catalizado por la VIII reunión del Foro Internacional Paulo Freire. Todo comenzó en 2003 en un viaje que conectaba Oporto en Portugal con Salgueiro en (Pernambuco), Brasil. Mirando hacia atrás hoy, me doy cuenta de que este ensayo fue un punto de inflexión, una conciencia de lo que habíamos compartido hasta ahora y todas las ofertas que recibí de la comunidad quilombola de Conceição das Crioulas durante el viaje a Salgueiro. En mi equipaje llevé conmigo, no solo las enseñanzas y la pedagogía criolla de Paulo Freire, que aprendí dentro de la comunidad, sino también el temor a la responsabilidad que quería asumir. Quería vivir en la comunidad de Salgueiro para estar presente, sentir el ritmo de su vida cotidiana y asimilar el mundo que me rodea intentando reinventarme diariamente en esta pequeña partícula que es global.

Paulo Freire. Pedagogía Crioula. Escuchando.

\section{A MEDO}

Começo esta escrita com medo. Acontece, por vezes, dizer em voz alta tudo aquilo que vou escrever, mas quando começo a tarefa da escrita as 
minhas mãos tremem e suam, a caneta escorrega, o pensamento acelera e dilui-se a certeza do que tenho para dizer. É nessa incerteza que se desenvolve esta apresentação.

Quando o texto surge, sou capaz de ficar horas a observar os espaços vazios entre as palavras que compõe a forma, na procura do sentido do que está dito e o que falta dizer. Um exercício constante entre o pensamento, a mão e a escrita. Atrevo-me a dizer, a medo, que a busca de sentido na escrita existe algures entre o sentimento, o dizer, o ouvir e a sua interpretação. A escrita surge assim como um desafio que ao desenrolar-se se descontrola, mas que a posteriori se domina através da revisão, correcção e na reescrita. Qualquer coisa muito próxima entre a vida, a memória e a imagem, construção visual que retrata a vida.

Foi na comunidade quilombola* da Conceição das Crioulas que conheci Paulo Freire. Conheci-o sem o encontrar, esse conhecimento travouse devagar, ao longo do tempo, e encontrei-o na voz da comunidade.

Tento afincadamente contar da maneira mais profunda, mais sincera, mais completa a força e a luta desta comunidade, no entanto é neste esforço que encaro a dificuldade de fazer ouvir aquilo que só a presença permite. De forma que qualquer conto que aqui apresento só se completa numa visita à terra que fala e pede para ser ouvida.

\section{Em movimento}

Tudo começou em 2003 numa viagem que aproximou o Porto, Portugal e Salgueiro no Estado de Pernambuco, Brasil. Nessa altura eu frequentava a licenciatura em artes plásticas, escultura, na Faculdade de Belas Artes da Universidade do Porto e começava os meus primeiros passos dentro do movimento intercultural IDENTIDADES, um movimento que a Universidade do Porto, Portugal, acolhe como espaço de partilha de conhecimentos e experiência teórico-prática e que se estende a Cabo Verde, Moçambique e Brasil. O IDENTIDADES conheceu e envolveu-se a partir deste momento com esta comunidade a convite do Centro de Cultura Luiz Freire, sediado em Olinda no estado de Pernambuco. Neste primeiro contacto este intercâmbio foi representado por mim, pela Iva Viana, ambas do Porto e Rogério Manjate de Moçambique.

Nesse ano, na Conceição das Crioulas, discutia-se 'que escola queremos nós?', lembro-me de ver vários grupos em reunião, as lideranças que comecei aos poucos a conhecer, que se compõem pelos mestres, as pessoas mais respeitadas da comunidade, foram chamadas a dar a sua opinião e estavam lá, todas presentes. Mas não pude ficar para ouvir, assisti o pouco que pude, curiosa pela energia que sentia latente num 'alguma coisa 
acontece.' Nos quinze dias que ali passámos, orientei com a Iva uma oficina livre de artes plásticas para crianças, jovens e adultos, ou seja, para quem quisesse participar.

O Rogério orientou uma oficina de teatro que culminou na apresentação da história da formação da comunidade da Conceição das Crioulas. Remeto estas várias situações, agora, para a conversa de despedida que tivemos, despedida que surgia mais como vontade para voltar. Quando nos sentámos para conversar sobre um possível futuro entre nós a frase que retive foi 'queremos ser nós a contar a nossa própria história, queremos aprender a gravar e a editar filmes para saltarmos para a net e abrir as portas da nossa terra. Queremos autonomia e contar o que sabemos.'. Se calhar não foi bem por esta ordem de palavras, mas foi assim que eu retive a força das palavras do que ouvi e é assim que a memória recria.

O que acabou por acontecer, a partir do contacto que mantivemos nos dois anos seguintes, foi que em 2005 nesta parceria, organizámos uma oficina de vídeo que fez nascer o 'CrioulasVideo', uma equipa de documentaristas quilombolas que ainda hoje se mantém activa e que dá formação noutras comunidades quilombolas, contando diariamente a sua história através dos relatos dos seus habitantes.

Sei que é desde 2003, e é uma certeza, que tomo consciência, participo, assimilo, observo, questiono, distancio-me, da importância que esta comunidade tem para o meu crescimento enquanto artista, professora, estudante mas fundamentalmente enquanto pessoa social e interventiva. $O$ ritmo com que se mostra este lugar é marcado pelo dia, pelo sol, pela noite e pelo céu estrelado, em conversas longas e pausadas, cantadas, prolongadas. Tudo ali é um conto e um canto. É assim que ela se apresenta, cresce, se mostra firme, madura e árvore. E é assim que enfrento o medo, nesta certeza e com este registo, o de aprender a ouvir, com a certeza que a consciência de estar alerta leva à transformação.

A partir das leituras que vou fazendo, gostaria de transportar para aqui algumas palavras de Krishnamurti, autor e teósofo hindu, na sua publicação A Mente e o Medo onde podemos ler 'Acredito, o importante é que "escutemos" a revelação desse estado, absorvendo-a como quem contempla um belo quadro, ou como quem ouve o canto de um pássaro; e se sabemos escutar verdadeiramente, o próprio escutar, a própria percepção realiza algo radical.'. Para o meu crescimento enquanto pessoa mas também enquanto investigadora, tendo em conta que na prática me movo constantemente em contextos interculturais e interdisciplinares, atravessar vários pensamentos que se encontram no mesmo espaço de partilha na busca da sabedoria, sublinha o espaço intercultural que pode ser encontrado na leitura e enquanto sustento para a minha investigação teórica. 
Houve tempos em que de forma tão séria e sincera absorvi a vontade da comunidade sem entender que o verdadeiro sentido do direito à liberdade de pensar, é um lugar que permite o direito de cada um contar a sua própria história, ou seja, não me senti com o poder de eu mesma ser autora, e com isso, ter o direito de contar a minha própria história. O medo, ou a incapacidade de me ouvir dentro da mesma paisagem provocou um sentimento ou uma voz que me dizia que seria uma espécie de falta de respeito se o fizesse, dessa forma sempre me coloquei distante de narrar a história que fizemos juntos, em que participei. Como se esta não fosse a minha história, mas a partir do momento em que abro os meus ouvidos, os meus olhos, as minhas mãos fica difícil manter a boca fechada. Encontrei um sentido e abri-me à pertença daquele lugar, daquela história e qualquer coisa mudou em mim.

Defendi o Mestrado em Ensino das Artes Visuais em 2010 na Faculdade de Psicologia e Ciências da Educação da Universidade do Porto com a camisola que as professoras da comunidade vestem no dia a dia na escola e que tem escrito 'cada um tem o direito de contar a sua própria história' e foi desta maneira que comecei a encontrar-me frente a um público que recebia a experiência que obtenho da partilha que tenho do mundo. Foi assim que comecei a contar o que aprendi e a transformação que deixei fosse operada em mim.

Este percurso de transformação pessoal senti-o a ganhar forma em 2008 quando juntas organizámos um programa para a formação de professoras para pensar o currículo das expressões artísticas dentro das escolas da comunidade que permitisse pensar o currículo diferenciado, intercultural e identitário dentro do Projecto Politico Pedagógico. Em 2010, no Encontro Internacional sobre Educação Artística que aconteceu em Cabo Verde, M_EIA (Escola Internacional de Artes no Mindelo) eu, a Joana Mateus do IDENTIDADES e a Márcia Nascimento da Conceição das Crioulas, apresentamos algumas das nossas reflexões sobre este programa. Um programa dirigido às professoras e a todos os intervenientes que desenham o caminho que a escola pretende assumir na comunidade.

Pensei que ouvia desde a primeira vez que lá fui, mas na verdade percebo hoje que quando parei para realmente escutar, vi que a comunidade cresce numa busca descendente, em direcção às suas origens e às suas raízes. Ela sabe que fortalecidas na base se ramificam com mais vigor, com mais força e que se torna mais resistente às adversidades temporais. É uma luta constante o seu dia-a-dia. Pelo direito à terra (que suporta a raiz), à educação (que orienta 0 crescimento) e à saúde (que garante a continuidade). Desta forma, não se prende apenas aos seus costumes, assimila o mundo que a rodeia procurando reinventar-se todos os dias nessa partícula global. 
Entendi assim que ouvir é o método fundamental para se atingir um objectivo. Se nos ouvimos todos os dias temos a capacidade de nos questionarmos, de nos entendermos e de nos orientarmos na mesma direcção. Crescer na busca de saber é o que nos torna conscientes e críticos. Conceição das Crioulas procura, constrói e reconstrói a sua identidade e oferece a sua sabedoria ao mundo e dele absorve.

Desta forma e com esta aprendizagem também procurei conhecer as minhas raízes. Venho eu de uma família contadora de histórias, de um meio rural, onde a família era composta por todos os habitantes da rua. Ao crescer mudei-me para a cidade para continuar os meus estudos e aos poucos fui assimilando outro tempo de estar no mundo. Não me apercebi que na cidade existe muito pouco tempo para escutar, a falta de silêncio é a ocupação central na actividade do dia-a-dia, estamos sempre a ser bombardeados por informação, que resulta na falta dessa mesma informação, saltamos de teoria para teoria, numa busca incessante de estar em todo o lado ao mesmo tempo, de falar de qualquer assunto com toda a capacidade aglutinadora de um resumo que apresente um domínio dos acontecimentos, passados, actuais e futuros. Todos os dias conhecemos alguém novo que surge e desaparece com a mesma rapidez com que surgiu, aos poucos esquecemonos da nossa própria raiz, da nossa própria identidade. Consideramo-nos cidadãos do mundo e esquecemos a casa que sustentamos, fica ela perdida ficamos nós também.

Quando ingressei na escola, deixando de ser estudante para ser professora dei-me conta da angústia desta profissão diária, e quando voltei para fazer o Mestrado e completar a minha formação com a pedagogia que faltava apercebi-me ainda mais da surdez com que se fundamenta esta profissão. Numa relação escolar com aqueles que decidem, as directrizes impostas pelo Ministério da Educação colocam os professores num papel de burocratas, reduzindo a importância das suas acções ao preenchimento de um conjunto de papeladas e burocracias. A preocupação maior é ocupar o tempo de cada um a fazer uma coisa qualquer sem a preocupação que seja ela relevante. Por sua vez, esta obrigatoriedade, esta obsessão ocupatória transita do professor ao aluno que está na escola, este não pode nunca sonhar e divagar em assuntos que lhe preocupa, consoante a sua idade e os seus interesses e muito menos contar e contar-se a sua história, é necessário ocupá-lo, enchê-lo de papéis para preencher impedindo assim que se atinja um estudo que seja algo mais profundo. Existe uma verdadeira educação quando tanto o professor como o estudante tem a liberdade de ser educado ao mesmo tempo.

\section{Uma pequena história}


A minha mãe foi das primeiras contadoras de histórias que conheci. Essas histórias falam de um crescimento de luta e de conquista, de dor e de medo, numa constante transformação de olhar para as coisas que temos com um olhar novo re conhecendo a partir da memória mas re construindo a realidade no presente que se mostra orgânico no futuro. Numa das histórias que a minha mãe contava encontrei uma similitude à árvore que encontrei na Conceição das Crioulas.

O meu avô foi em tempos guardador de árvores, num tempo em que a electricidade era pouca ou quase nenhuma e a paisagem era pontuada por uma casa aqui, outra acolá. A casa onde a família se fixou ficava dessa forma isolada e rodeada de árvores. No inicio foi divertido, passavam horas a brincar por ali, a ver como se comportavam os coelhos bravos que abriam túneis fantásticos entre as raízes das árvores por onde muitas vezes eles, os filhos, se deixavam engolir, divertindo-se. Passado algum tempo, num outro tempo o meu avô começou a beber sem controlo, passando a viver a partir daí, esquecido. À noite quando regressava a casa, acontecia procurar a sua esposa com agressividade e encontrava nela a razão suficiente para libertar a sua raiva. Era noite, em frente à casa havia um lampião que iluminava um pouco a casa e o pinheiro, que ficava entre a casa e o portão da rua. $\mathrm{A}$ minha avó encontrava assim um ponto de abrigo. Ao fugir, a sua fuga consistia em sentar-se encostada ao pinheiro, na sombra que a luz provocava na árvore, e ali ficava estática entre o olhar a sua casa e o desolhar do marido, até que este se cansava e desistia.

Diva é hoje professora na escola Professor José Mendes, na Conceição das Crioulas e é uma das iniciadoras do movimento da escola na comunidade. Ela tem a sua casa num sítio território limite entre o território quilombola e o território indígena. Ali mesmo tem uma árvore, um umbuzeiro, abrigo, sala, ou lugar iniciador das primeiras reuniões para o estudo e os encontros de partilhas de saberes. $\mathrm{Na}$ altura da demarcação do território indígena, a linha limite do território passava mesmo no meio do umbuzeiro, a ordem que receberam foi que tinham que abater a árvore. Até que chegou o dia, e a Policia acompanhou o processo de abate do umbuzeiro, o marido de Diva saiu de casa em defesa da árvore argumentando que servia para cuidar do gado que tinha ali, mas os argumentos não serviam para demover das ordens que havia. Não sendo possível entortar a linha que marcava o território, ele pediu que cortassem o umbuzeiro assim mesmo, na vertical. Hoje, o lado que ficou no território indígena desapareceu, mas o que ficou no território quilombola cresceu e hoje é o ponto de encontro dos artistas e das artistas, que se juntam para tocar e dançar.

\section{A ouvir}


A consciência activa a liberdade que precisamos de ter para poder ver tudo como novo. A nossa memória é um óptimo instrumento de recolha, selecção, acumulação, capaz de provocar medos e ansiedades, muitas vezes levando-nos a procurar sistemas de maior protecção fechando-nos a capacidade de re olhar, re ouvir, re sentir como algo que se re nova e se apresenta como se fosse a primeira vez. A informação que guardamos na nossa memória permite-nos sobreviver face as adversidades da vida, mas impede-nos muitas vezes de nos renovar. Essa defesa provoca-nos um sentido de procurar métodos e modelos como sendo a forma mais eficaz de nos orientarmos, de nos definirmos, de nos fazermos entender, limitando muitas vezes a nossa capacidade de actuar.

A liberdade da gestão do tempo. 'Para ler é preciso estar parado' e para ouvir? É na pausa, na contemplação, no parar, é nesse movimento que se encontra o 'eu' e com ele o sentido social, o estar entre. Na tentativa de estar constantemente ocupado perde-se também o sentido de comunidade, perde-se a noção de grupo, a pertença do contexto e do texto em que nos lemos. Na procura de definições buscamos constantemente um método, muitas das vezes encaramos esse método como sendo fixo, que permite a cópia e a repetição constante. Motivados pelo desejo de resolver uma dor ou uma situação pontual, avançamos com a rapidez de encontrar um lugar seguro, prendemo-nos a fórmulas procurando assim atingir o objectivo de dar respostas seguras a um poder que se mostra dominante. Seja ele um poder político, económico, social ou pessoal. É, no entanto, na abertura, na pausa, no exercício de manter a consciência activa de perceber o real que se baseia e que se encontra a arte do encontro, do crescer e da identidade que se procura.

Termino por hoje sabendo que quando encaramos um grupo novo, uma situação nova, o medo encontra-se lá também. E é nessa incerteza que se desenvolve o contacto, as mãos suam, a voz parece que não quer sair, o pensamento acelera, o coração também. $E$ é entre pausas e silêncios que se marca o ritmo, a vontade, a partilha. Esse espaço vazio permite entender 0 que se diz. E é aqui que acontece a transformação.

A sala de aula não é um dado adquirido, a escola também não. A constante aproximação/afastamento, falar/ouvir, espaços vazios/cheios é o que define o meio em que nos colocamos. Atrevo-me a sair, a medo, na busca de um sentido na construção da escola que se assente entre o sonho, o dizer, o ouvir e a terra. A educação surge assim como um desafio que ao desenrolar-se se descontrola mas que a posteriori se domina através da re visão, do re olhar, do re ouvir. Qualquer coisa muito próxima entre a vida, a memória e a imagem, construção visual que retrata a vida.

Ali conheci Paulo Freire porque muito provavelmente foi ali que Paulo Freire se tornou ouvinte. 